\title{
Impact of Digital Economy on Intellectual Property Law
}

\author{
Asif khan ${ }^{1} \&$ Ximei $\mathrm{Wu}^{1}$ \\ ${ }^{1}$ School of Law, Zhengzhou University, Zhengzhou, China \\ Correspondence: Ximei Wu, Professor at School of Law, Zhengzhou University, Henan, China. E-mail: \\ zzueducnwxm@163.com
}

Received: August 30, 2020

Accepted: October 4, 2020

Online Published: October 13, 2020

doi:10.5539/jpl.v13n4p117

URL: https://doi.org/10.5539/jpl.v13n4p117

\begin{abstract}
Intellectual property is regarded to be the digital economy's hot issue. It ranges from theoretical arguments to own information concerning everyday life relating to the foundation of internet geography. The current study deals with the impact of the digital economy on intellectual property law and proposes that although various countries have given many intellectual property laws, no such implementation has ever been made. Still, the digital world has witnessed the protection of intellectual law through technical protection and contracts. The digital economy has greatly impacted the intellectual property law that can be witnessed through cyber squatter legislation and significant legal and economic protection developments. The endorsement of business methods patents and ecommerce would significantly affect freedom, computer as well as privacy. However, some of their personal information has been suggested by giving individual property rights while describing it to protect freedom and privacy. In this study, it has also been concluded that policy is critical to conceive and analyze issues so that it would be technology independent. It would help policymakers to draft legislation and policies in the same way. In addition to this, policymakers' decisions should not base on any business model's specifics only. Moreover, the study suggests the need for other adaptations to ensure that all the essential purposes in copyright laws, such as giving free access to the public for a broader range of information, have been adequately fulfilled in the digital economy context. However, such adaptations are yet to design, and for completing such tasks, the stakeholders' participation is significant.
\end{abstract}

Keywords: copyright issues, digital economy, e-commerce, intellectual property law

\section{Introduction}

For IP (Intellectual property) law, challenges have been posed by advances in technology. Copyright law has been amended periodically by Congress to regulate technology products such as sound recordings, photos, cable TV, motion pictures, or new work uses, which are made possible due to technological advances. (Nimmer, 1996) Copyright litigations such as those involved in scientific articles' photocopying and home videotaping, emerge due to new technologies. In IP law, perturbations would be brought by the advent of networks and digital technologies, which is not surprising. Software patents and copyrights were focused on the first set of battles over digital information and copyright (Litman, 1994).

These battles have now resulted in a new status quo as they are intense in their day. Recent battles over the role of copyright on the World Wide Web and Internet have become more intense (17 U.S.C. sec. 106(1)). Underlying these debates, identifying the importance and difficulty level of these issues, the National Science Foundation acted on a suggestion provided by the Federal Networking Council Advisory Committee. It commissioned a study of IP and new technology issues by the Computer Science and Telecommunications Board of the National Academics (Levy, 2000). A committee on the Growing Information Infrastructure and IPR (Intellectual Property Rights) was established in 1997 by the Computer Science and Telecommunication Board of the National Research Council to consider the policy implications of information technology advances for intellectual property law. After two years of work, the committee issued a report named The Digital Dilemma: Intellectual Property in the Information Age. (Samuelson, 1996; Zech, 2015). In this article, reasons have been offered why the digital economy has been causing problems in intellectual property law, and it also inferences how digital dilemmas can be addressed. Many stakeholders, economists, freelance authors, network experts, computer scientists, academia and industry's IP lawyers, publishers, database specialists, librarians, editors and telecommunications, digital and cryptography libraries, and the committee were thoughtful. (Litman, 2010) 
Along with that, the committee heard from an extensive range of government, academic and industry experts. Deliberations of the committee were most severe, which reflects the strong positions of most of the problems. We believe that the report performs various vital functions. Firstly, it is the issues' objective evaluation and explanation via which the reader gets alert to the lasting results. It recommends the process of speaking about the problems when the consensus was probable (Nimmer, 1996). In other cases, when consensus is not possible, it gives contradictory views' outline and surface expectations underlying various positions. It identifies the data that needs to be collected and for research in various areas to inform future decisions, and it outlines an agenda. Digital dilemma poses difficulties, and for thinking about them, it gives framework. It then urges thinking about the stakeholders' extensive range, the array of forces at work and perspectives through which one should see problems. The report is regarded as groundwork for substantial hard work that needs to be done and work that needs all affected populations' participation (Zech, 2016).

\section{The Promise and Perils of Digital Information}

To content consumers and content creators, both peril and promise are brought by the information age. An unlimited audience can get online information from anywhere there is a network or telephone connection. This is great news at first glance. There is the continuous availability of libraries' electronic holdings for the information consumer from a home computer. (Samuelson, 2003) The information technologies provide new markets and chances for both publishers and authors. However, there also exists a bothersome side. The question for authors and publishers is: if planet-wide access to any work's electronic copy is made possible, how many work copies will be sold? (Kim, 2018).

The thing which is terrifying for them is that the number is one. Suppose the entire market can be extinguished by the first electronic copy's sale to a public library. How many books or photographs, movies or musical pieces will be formed online and published as well? for consumers, the nightmare is that new commercial market areas are attempted to be established and protected by the author-publisher so that their work can be exploited. The results in legal and technical protections which reduce access to the cultural and intellectual heritage of society. For the largest reproduction facility of world and information publishing, a strong medium is nowadays information infrastructure. The technology can improve access to information, and it also still offers the probability of refraining access in previously unrealistic methods (Kerber, 2017). It can provide access to information resources of the world to millions who previously did not have access. It has the potential to be stratified, extending the wellrecognized divide between the information "haves" and "have-nots." Today's information infrastructure can demolish a careful balance of public good and private interest at the US intellectual property law's core over the past two hundred years.

The betterment of society is the public good, resulting from promotion, as said by the Constitution, "progress of science and the useful art" (Council, 2000). Grant of a time-limited monopoly has given rise to the private interest to those who played their role in that progress. By offering enough control to motivate inventors, authors and publishers, the classic challenge has been to strike and maintain a balance between these interests and form and distribute works. Control should not be much so that policy goals such as broad access to information, the nation's cultural heritage's preservation and education and scholarship's promotion can get threatened. As usual, the devil is in the details, but in the last two hundred years of IP history, these details have been widespread but have been successful in most cases (Levy, 2000; Kerber, 2016). In technology, a leap is presented by the information infrastructure by which current balance may get upset, requiring fundamental practices and premises' re-evaluation connected with intellectual property. In social and economic terms, the stakes involved in all this are high (Yen, 2000). Who will take advantage of the technology will be determined by the decisions made soon and now. It will also identify who will be granted access to what kind of data on what terms- the future's foundational components as an information society. As a society, we need to ask whether there is still functionality of existing mechanisms or not; if not, then what is the solution so that we get able to form information society's kind we want to get. In the digital age, forgetting the intellectual property policy and law's goals, what options exist? (Hoeren, 2014).

\section{3. (Why) Is There a Problem?}

It is essential to be clear about the issues' nature. Current concern gets motivated, given how to two years of technological change, IP has adapted itself and given the frequency with which someone suggests that IP is in trouble. Comprehending the root causes of the problems helps make sure that suggested solutions are exactly harmonized to the problem. In the course of the work of the committee, key explanatory components are two developments that arose. In the economics of controlling, reproducing, allocating and publishing information, radical shifts have been produced by technological advances' trio. Secondly, in everyday life, the information infrastructure has become an important element, so it runs abruptly into intellectual property law as it did never 
before. (EC, 2019) In the economics of information, a trio of technological advances which have led to radical shifts are: 1) economics of reproduction have been changed due to information in digital form, 2) economics of distribution have changed due to computer networks, 3) economics of publication have been changed due to World Wide Web. Reproduction's cost and difficulty are reduced radically by the digital form's information. Perfect replicas are also produced by it, each of which is a root for further flawless copies. Reduced production costs are an evident benefit of these right holders' characteristics (Yen, A. C. 2000). From low cost, infringers also get an advantage, perfect digital copies. Erosion of previous natural barriers to infringement, namely, reproduction's expense and reducing the quality of copies' consecutive generations in analogy media, is an important result. The balance struck by IP gets upset in turn, which, same as all other laws, is built on understood assumptions about the trouble of violating the law and expectation that many persons will not have access to technologies that by a trivially easy act private enables infringement to be accomplished. Access to digital information unavoidably demands making copies even if that information's ephemeral copies; this is a reason that for IP policy and law, difficulties are presented by the information in digital form, by copying the program to memory from disk results in running a computer program (Council, 2000). To most computer scientists, this action seems insignificant. However, the courts have held that turning on a computer full of programs through a repair service that is not authorized to use the programs constitutes copyright infringement. They have become unauthorized copies of the programs made with random access memory to the computer. (Muth, 1983) While Congress overturned this specific ruling, the copyright importance of digital work's temporary copies has continued to be an argumentative problem in US copyright law. In the way computer works, getting access to digital information by making ephemeral copies is rooted deeply: to watch a movie, read a book, see any kind of picture, for making one or more copies and for listening to a song, the computer is used. Make its comparison with the traditional media: making a copy is not involved in a book reading, nor listening to a song, nor does watching the movie. There is noteworthy importance of the association between access and copying in the intellectual property protection context. The copyright law's hallmark is the right to control protected works in copies' reproductions. There is an evident difference between reproduction and access in traditional media's world, such that control over access is not generally provided by the copyright owner's control over reproduction. The law has quandary if reproduction is required by access. Right holders must have the right to control digital access, as stated by some professionals and copyright owners because it involves reproduction. Traditional public access to information in unique ways will be undermined if such rights are granted. As the digital economy has changed the distribution of information products, it has created difficulties. IP transaction's dominant model has been selling a work's physical copy for more than a hundred years. Rather than being sold, digital information is mostly licensed. Between two types of transactions, there is a noteworthy difference. From seller to purchaser, ownership rights' complete transfer is involved in sales. The sale of intellectual property products is anticipated clearly by copyright law because of its "first-sale rule" this law refrains copyright owners from controlling once sold publicly distributed copies (Farkas, 2017). The buyer is then free to rent, lend or re-sell the copy which has been purchased. IP products are followed in the marketplace by copyright law, and it also promotes the information's continued distribution. Libraries and bookstores are enabled to function free from copyright owner control due to the first sale rule. To use an item on stated conditions and terms, a limited transfer of rights has been constituted by Licensing. Contract law governs licenses as it is an important private agreement amongst two parties (Council, 2000). Matter of argument is that if policy considerations can get overridden by such licenses and to what extent. As compared to sales, drawbacks and advantages are given in detail by the report. Here, the point is simply that in transaction type, the difference is significant. The economics of distribution have changed radically by computer networks, which are the second essential technology development. People are enabled to send digital data worldwide in a cheap way, and almost no time via networks (Kim, 2018). As a result, it is easier for persons and commercial infringers to disseminate unauthorized copies as it is easier and cheap for rights holders to distribute work. The economics of publication has changed because of the World Wide Web, which is the third development as with global reach, it enables everyone to be a publisher. There is an amazing variety of opinions, works, articles and documents of all kinds, which shows that billions of people use this skill (Council, 2000). As it brings both challenges (in the publishing industry, current disruption) and promise (for example, majorly increased publications' ease), so it has a dual character. The information infrastructure has become a part of life as the world wide web, and the internet has become a mass phenomenon. In doing so, it can headlong in IP law. Intellectual property laws may get violated by ordinary individual actions such as sharing embroidery designs on a listserv or uploading or downloading playboy bunny photos' scanned copies as of these works, and they make consumable copies available due to which sales may get displaced over which there should be control of the copyright owner.(Eisenstein, 1980) A complicated and subtle interpretation of the doctrine of fair use of copyright law might be required to determine legality by submitting a copy of an article posted online to a friend. Several years ago, a large investment was needed for 
copyright, but today, with the help of his or her personal computer, the average person can do that easily. Some people are obvious about what is legal and acceptable in sharing or copying information on the internet. As current intellectual property law is intricate, it is not easy to provide a clear "bright-line" answer. The increasing importance of IP law in everyday life is a result of the information infrastructure's growth. Corporate battles among highly professional lawyers have an exclusive domain to discuss what is legal and acceptable in copyright matters; however, in popular press and living rooms, such kinds of debates are seen easily now. (Samuelson et al., 1998) There is growing concern among right holders about the enforcement of IP concerning private individual's behavior. On controlling protected works' public exploitation, copyright has focused more. It includes making sure that copyright owners have consented to the music's public performances and works' distribution. Firms or businesses whose actions had large-scale public results were mainly regulated by it. Ordinary individuals' small scale actions have got very less attention (Samuelson et al., 1998). The concern of right holders is that small scale infringements' proliferation by private persons may threaten the markets as communication and computer equipment have become common in the home. In copyrighted work's private uses, the interest of right holders has been increased. In everyday life, this was an important result of the emergence of technology, and in IP balance's management, it presents another policy and social challenge (Samuelson et al., 1998)

\section{Why the Problems Are Difficult}

For various reasons, IP law's information technology problems are challenging to find a complex solution for Intellectual property law. It is a collection of various special-case exceptions (at agricultural fairs, right to play background music), subtle distinctions (for example, "idea" versus "expression") and general principles (for example, reproduction's exclusive right). (Samuelson, 1999a). Even though the issues have arisen in daily life, people cannot deal with intellectual property law's intricacies. For example, an ordinary individual does not know that on two different computers, is it legal to install a software package is one copy or whether to make a music CD's private copy is legal or not. To such questions, mostly legal professionals disagree about the answers. There can be a different interpretation of the fundamental legal concepts, which gives rise to difficulty.

Various views are there for whether the "fair use" doctrine of copyright law is just a defense against infringement charge or an affirmative right that allows copying in specific conditions. (Lemley, 1999) For both pragmatic and theoretical reasons, the difference matters. It is acceptable to take positive actions such as avoiding technical protection mechanisms if fair use is an affirmative right so that fair use can be exercised. If fair use is just a defense against infringement, then the same act cannot be justified. The essential thing is very provocative. A notion that fair use can be an affirmative right is declared as "absurd" by one legal scholar while other scholars for affirmative fair use rights suggest a constitutional basis. Various stakeholders have different and sometimes opposing interests, so the problem gets more complicated. Almost everyone is included in the debate over intellectual property. It may include authors, publishers, consumers (public interested in listening, reading etc.), educational institutes, libraries, and governmental bodies (Lemley, 1999).

Another difficulty is that content creators have various motivations and different views on their investment, constituting a return. As a result, for the management of intellectual property, they have different tactics. IP law's view is encouraged as a foundation that provides exclusive rights by the traditional model- content formed and vended, either directly or advertiser support. (Lemley, 1994) Other models include giving away the intellectual property while expecting that in a related market, the benefit can be obtained indirectly and to enhance the community, IP's sharing (for example, providing open sources such as the Apache Web Server and Linux) or keeping it secluded (for example trade secrets) (Lemley, 1999).

Discussions about intellectual property (for example, in IP protection levels, the effects of changes) are often set in a single model's context, so the multiplicity of returns, actors, strategies, and motivations matters. It suggests that all parties get influenced equally by any kind of change in IP policy or law (Council, 2000). Authors are not a homogenous lot, and there may not be uniformity in IP policy decisions' results. A variety of threads tangled in this policy contributes to the complexity. For analysis of problems and estimating possible resolutions, each thread has its perspective. While discourse on intellectual property is framed mostly in legal terms, the appropriate discourse should be broader than that. At least five perspectives are very important: law, psychology, public policy, technology, economics and sociology (Council, 2000). For analysis of the problems, each perspective comes with its notion. These are useful in the disentanglement of the complications that are faced and should be kept in mind when solutions are evaluated (Council, 2000). For the average user, a technical mechanism seems to be awkward, although it is promising. Powerful forces can be exerted by economics, which is capable of beating law's good intentions; it has been argued the recent research that "with rent control rules, intended to preserve low-cost housing, which in some cities led to the conversion of many rental spaces to condominiums and resulted in a reduced stock of rental housing" (Council, 2000). 
The problem has an international nature: the digital economy is global, and yet to each nation, intellectual property laws are local. Around the world, in case of laws, there is substantial variation and also in enforcement policies and cultural attitudes towards IP. US practices and laws are focused on the report of Digital Dilemma but also admits that in many ways, large global issues are important, and it is unavoidable in many ways (Council, 2000). Digital dilemma issues are difficult because of the intensity with which all sides' positions are held and uncovered. On issues that invoke power balance elements, ownership and stakeholders' economic well-being, feelings run deep. Problems should not be viewed by any single lens or as solely as they are multi-dimensional. The committee contributes that a broad framework is urged to address issues of intellectual property policy that acknowledge elements' full breadth. (Samuelson, 1999b) Taking account of stakeholders' full-spectrum is required in public policy, and it also includes their contradictory goals. Seeing a dilemma in broader terms compared to law alone is required by significant public policy construction; it demands an understanding of forces' complete range. By using all perspectives required in pondering about issues, the analyses compulsory for policy creation will come. It will require the ability to think like psychologists, lawyers, policymakers, economists, and technologists (Samuelson, 1999b).

\section{Consensus and Nonconsensus On Public Access Concerns}

An essential objective of copyright law is public access to information which is published. Public access effective fundamental enabler is the publication's traditional model- circulation of work's physical copies. Published work's adequate number of copies are purchased via private individuals, institutions and libraries that it becomes part of the intellectual, cultural and social record. (Shapiro et al., 1998) It then becomes available to adequately public motivated individuals. A long-standing understanding exists that cultural and social records will continue to be preserved and accumulated. Ultimately, it will be available for discussion as this era is of public libraries, so access to mass media, college education and information has been amplified. Access to information has been promised to increase by information infrastructure's some features yet to reduce public access, and others have the probability. For the market for work, if only a single online work's copy is provided in the digital library's open access, then it would have devastating results such that publishers are unwilling to make work available in digital form in libraries (Shapiro et al., 1998). In information accessibility, a net decrease is a result. License's increased use, the publication is changing nature, and increased use of technical mechanisms to safeguard digital information products give rise to public access challenges. The publication is irrevocable and public in this physical world, and it also involves one or more fixed work copies' distribution (Shapiro et al., 1998). None of these may be correct in the digital world. Copies are disseminated widely, and they have also become part of cultural records, so publication has conventionally been public. Works may go out of print, so it can be said that publication has been irrevocable, but once work is published, then from circulation, it cannot be withdrawn and becomes "unpublished." Work's stability is implied by publication: at a specific moment, work's stable snapshot is provided by distributed copies; successive editions only add to this record. At the right holder's pleasure, documents posted on the internet and published can be deleted in the digital world. Access control can be exercised to allow for many diffusion and access gradings. (Hurwitz, 2005)

Along with that, new versions of documents can replace the older ones, thereby destroying various iterations' historical records. Between private and published information, this contributes to once firm distinction's blurring. This distinction matters because, in a published document, ideas and facts are available to be used by any individual. For public access, implications are the TPSs (Technical protection Services) and licensing's extensive use. To provide access to digital information's types, licensing has become a familiar mechanism, but it is relatively new for other types such as research journals. It has often stirred controversy even where the practice is familiar, as in shrinkwrap licenses' still-developing idea. Licensing can open new markets by offering a distribution model different from that represented by sale and copyright. (Samuelson, 1999b) Public access concerns are also raised by licensing and also about the material's healthy corpus's maintenance in the public domain, specifically where there is a difference between legal rules and license limits that would be applied otherwise. Change in the distribution model to licensing from sale challenges the role of libraries as a material's permanent repository that constitutes cultural heritage. Nature of libraries may become passing, for collection of information, temporary access points: available right now, but when the license expires, they are no more available. Material which license distributes may not become long-term public record's part, giving rise to extra concerns (Public Law 105 - 304).

To face critical issues related to digital content distribution without the possibility of large-scale unauthorized copying and reallocation, publishers use TPSs (technical security systems). To resolve critical issues related to digital information distribution without large-scale illegal copying and reallocation of risk, publishers use TPSs (technical protection systems). TPSs assure to right holders that digital work's single copy's distribution need not result in overpowering and limitless distribution (Hurwitz, 2005). New markets could be open, and TPSs could 
increase work's distribution of access by enabling information products' network dissemination, which would never have been digitally circulated. Otherwise, for some works, it may be decided by some right holders to avoid digital distribution altogether. On content distribution, limitations may be allowed by technical protection services such that it cannot be shared with consumers but can only see it. It is being planned by a few content developers to circulate digital data that can only be viewed by users but cannot be saved or printed. The publication's role may get defeated by the inability to share information, which contributes to permanent, shared, cultural and social heritage. An increase could be seen in the audience- and time-limited distribution. The fundamental pact between authors and society, which is part of copyright, is undermined by highly constrained models of TPS, as stated by some committee members. It is a pact that encourages that for the benefit of society, creation and distribution are essential. It is the concern of individuals that the limited distribution model of publication may undermine a constitutional intent. These are rights granted to authors for a shorter time in exchange for an assurance that eventually, materials will pass in the public record and public domain. On the following points, the consensus was reached by the committee.

Conclusion: in the world of physical artefacts, the convention of providing limited access to published materials was established. This tradition must be continued in the digital context. In response to the digital intellectual property and information infrastructure, the mechanism for attaining this access and the "limited degree's" definition need to evolve.

Recommendation: As information infrastructure causes fundamental changes, various stakeholders need to reevaluate and clarify the publication's concept in response to these. There is also a need to determine the implications of the public policy of publication's new concept.

Conclusion: the meeting of three developments- in the digital world, the publication's changing nature, instead of a sale, licensing's increased use instead of sale and technical protection services' use- creates unprecedented options for individuals so that information can be accessed in a novel and improved ways but on information's public access, it could have a negative influence. There should be close monitoring of developments over time. (Hurwitz, 2005)

For digital information, from non-negotiated licenses, concerns about public access arise. Whether the terms of mass-market licenses offered on a leave-it or take-it basis should override fair use or other copyright's limiting policies is the principal issue. In the law, the question is unresolved and controversial as well. Sufficiently important are the public policies connected with intellectual property law that mass-market license terms should not be allowed to override them. (Samuelson \& Davis, 2000) For computer software, the enforceability of a term in the mass-market license is questioned by innovation and public policy favoring competition. It forbids software reverse engineering. If digital information product or its flaw's disclosure's criticism is forbidden by mass-market license, then the critical analysis is encouraged by fair use. Whether fair use should be applied or not is unclear if works are licensed. The committee did not reach a consensus on these issues. (Samuelson \& Davis, 2000) The mass-market license must be subject to fair use limitations as suggested by some committee members, viewing fair use and other copyright is limiting doctrines as having a strong character (for example, under copyright law, providing rights for users instead of just defense to the infringement). For society, critical tasks are ensuring intellectual discourse's record and archiving cultural heritage. It also faces challenges from digital information's nature and licensing use rather than information products' sales.

Conclusion: If archiving institutions and libraries are to be successful with digital information as they have been with hardcopy information, it is essential to solving legal, economic and technical issues.

Recommendation: For archival purposes, congress should enact legislation to allow digital information's copying, whether the copy is migrated to a new format or remains in the same format. To determine shape, desirability, system's funding requirement and feasibility, a task force on electronic deposit should be chartered for the deposition of digital data files in various depositories. (Samuelson \& Davis, 2000)

\section{Consensus and Nonconcensus on Individual Behaviour and Copyright Issues}

How frequently copyrighted materials are duplicated and whether they stop to think that whether it is legal or illegal to do this act, very little is known about it. Many people assume that making private copies is their right, and by IP law's substantive knowledge, their view about appropriate conduct is not shaped. About the scope of private use copying, which occurred, the committee was not in agreement.

Conclusion: Of public perception and behavior regarding digital intellectual property, a better understanding is required.

Recommendation: to develop a better understanding of digital copying types' which people think are allowed, what 
they regard as ill-defined areas and what they regard as infringements, data collection, and research should be pursued. How these views are different in various communities and how they differ according to material types (for example, online documents, software and recorded music) should be researched. Research should be done on how user beliefs are followed by user behavior and how user behavior is changed by knowledge about copyright law.

It is not easy to understand how to talk about challenges posed by intellectual property law's emergence in individuals' lives without correctly understanding these issues. To digital intellectual property, whether and to what extent copyrighted material's private use copying is fair or not unique. It is the ease with which one can make digital copies and distribute them. It makes private use copying very extensive in the digital environment.

The Committee reached a consensus that neither extreme position on legal or private use copying issue is correct. Against the fair-use and private-use position, the report sets forth an argument. However, more correct is taking no position as on the issues, as the committee members differed among themselves regarding the issues. Nevertheless, conclusions and recommendations were not offered by the committee.

Conclusion: In society, an extensive belief prevails that private use copying is always lawful. On ethical and legal grounds, this view is not easy to support. Finding ways for convincing people to consider the economic, ethics and legality implications of their private copying's acts is essential.

Conclusion: Copyright law's fundamental purpose and competing interests' concomitant balancing among stakeholders derive fair use and other copyright law exceptions. Methods by which one can achieve copyright's exceptions and fair use are affected by the evolving information infrastructure, but it does not challenge underlying public policy motivations. In the digital environment, copyright law exceptions and fair use must continue to play their role.

Conclusion: it may be necessary to provide additional statutory protections on copyright so that the digital environment can adapt copyright appropriately. A useful mechanism is the doctrine's fair use (Hurwitz, 2005).

Recommendation: to identify the extent to which fair use and other limitations and exceptions to copyright must be applied in the digital environment. The scope of fair use and other copyright limitations are shaped by the marketplace, public policy research and legal developments. They also exhibit the need for additional actions and protections, which may be required for adopting a law, educating people about it, and law enforcement may become evident. To safeguard digital data and enable right holders to understand intellectual property assets' commercial value, there is no need to do "heavy lifting" by copyright law. In a digitally networked environment, both technical protection and business models have a role to play. The best way for right holders could be a good business model to avert digital data's perils and realize the digital assets' commercial value. It is helpful to think about business models as a method via which digital data can be protected because, in this way, available options get extended. For some products, the conventional business model of selling digital data may still function. These products include selling musical recording CDs. Attempt to control digital data may be de-emphasized by other feasible business models, and they focus on services or products for which digital IP is complementary.

By considering that from IP, what kinds of value can be derived, business models can be produced which are difficult to reproduce and even from those properties that play their role in making digital IP to be shared and copied so quickly, what forms of value can be derived. For deriving value from digital intellectual property, effective means are business and technology models, both. The need for legal and technical protection can sometimes be reduced sharply by an appropriate business model, yet from IP, a way can be provided to derive substantial value. (Council, 1991) Models through which this objective can be accomplished range from the traditional sales model (price is low, mass-market dissemination with convenient buying, where buying is made more attractive as compared to copying by the ease of buying and low price), to the more radical step of giving away data and selling a complimentary service or product (for example open-source software). To all the power offered by business models to deal with digital data dissemination, right holders should give vigilant attention. However, the model must be sensibly matched to the product: while there are some products for whom the suitable business model may remove the need for technical protection.

In contrast, protection may be compulsory for others, and even the most solid mechanisms of protection probable to be available soon may not be adequate. The technical protection can play various roles for intellectual property products: from aiding right holders to collect profits to protecting user privacy to ensure the authenticity of the information. These measures cannot resolve underlying intellectual property, economic, legal or social issues, but they can help implement some constraints, rights, responsibilities and rules. For distribution through digital networks, every information is not suitable, given that alternative mechanisms' availability offers many advantages while risks offered are significantly less. From digital networks such as the internet, considering withholding long- 
lived and high-value commercial products (for example, "The Wizard of Oz") (Council, 1991) is a sensible decision by rights holders because of the results of someone catching bits for re-dissemination are massive. The legal, technical and social enforcements costs are to ensure that such harm might be prohibitive. For every content form's mass marketing, the information infrastructure may not be safe. The committee's conclusion is stated simply: using physical substrates, and it would be more secure to distribute some digital information instead of by computer networks.

Among computing professionals, it cannot be denied that another technology can avoid any technical measures through which copyrighted works can be protected. Digital works will be exposed to piratical copying once there is a bypass of technical protection measures as if they had never been safeguarded. Once copyright industries recognized it, they successfully sought legislation so that both the distribution and sale of circumvention technologies and the act of circumventing some types of technical measures can be regulated (Samuelson, P. 1996).

\section{Conclusion}

It can be concluded that the digital age will indeed be survived by Intellectual property law. However, the laws need to be appropriately implemented to ensure sufficient protection for right holders and content creators. It would play an essential role in ensuring that diverse and extensive supply of information work is available to the people. There is also a need for other adaptations to ensure that all the essential purposes in copyright laws, such as giving free access to the public for a broader range of information, have been adequately fulfilled in the digital economy context. Such adaptations are yet to design and to complete such tasks; the stakeholders' participation is significant.

\section{References}

Copyright law 17 U.S.C. sec. 106(1). Copyright law confers on authors an exclusive right to control the reproduction of their work in copies.

Council, N. R. (1991). Intellectual Property Issues in Software. National Academies Press.

Council, N. R. (2000). The digital dilemma: Intellectual property in the information age. National Academies Press.

EC (European Commission). (2019). Building a European data economy. Retrieved May 22, 2019 from https://ec.europa.eu/digital-single-market/en/policies/building-european-data-economy

Eisenstein, E. L. (1980). The printing press as an agent of change. Cambridge University Press. https://doi.org/10.1017/CBO9781107049963

Fallone, E. A. (1993). Neither Liberal Nor Laissez Faire: A Prediction of Justice Ginsburg's Aproach to Business Law Issues. COLum. Bus. L. REv., 279.

Farkas, J. (2017). Data Created by the Internet of Things: The New Gold Without Ownership. Revista La Propiedad Inmaterial, 23, 5-17. https://doi.org/10.18601/16571959.n23.01

Hoeren, T. (2014). Big Data and the Ownership in Data: Recent Developments in Europe. European Intellectual Property Review, 36(12), 751-754. https://doi.org/10.17104/9783845255439

Hurwitz, D. S. (2005). A Proposal in Hindsight: Restoring Copyright's Delicate Balance by Reworking 17 USC Sec. 1201. UCLA Ent. L. Rev., 13, 263.

Kerber, W. (2016). A New (Intellectual) Property Right for Non-Personal Data? An Economic Analysis. GRUR Int, (11), 989-1096.

Kerber, W. (2017). Rights on Data: The EU Communication "Building a European Data Economy. In S. Lohsse, R. Schulze, \&D. Staudenmayer (Eds.), Trading Data in the Digital Economy: Legal Concepts and Tools (pp. 109-135). Baden-Baden: Nomos. https://doi.org/10.5771/9783845288185-109

Kim, D. (2018). No One's Ownership as the Status Quo and a Possible Way Forward: A Not on the Public Consultation on Building a European Data Economy. Journal of Intellectual Property Law and Practice, 13(2), 154-165. https://doi.org/10.1093/jiplp/jpx215

Lemley, M. A. (1994). Intellectual property and shrinkwrap licenses. S. Cal. L. Rev., 68, 1239.

Lemley, M. A. (1999). Beyond preemption: The law and policy of intellectual property licensing. Cal L. Rev., 87, 111. https://doi.org/10.2307/3481005

Levy, S. (2000, March 7). The Man Can't Stop Our Music: A Little Program Called Napster Could Shake, Rattle and Roll the Music Industry-And the Net. Questia. Retrieved from https://www.questia.com/magazine/1G160524295/the-man-can-t-stop-our-music-a-little-program-called 
Litman, J. (1994). The Herbert Tenzer Memorial Conference: Copyright in the Twenty-First Century the Role of the Copyright Office. Jessica Litman: Exclusive Right to Read. Retrieved from http://wwwpersonal.umich.edu/ jdlitman/papers/read.htm

Litman, J. (2010). Readers' Copyright. J. Copyright Soc'y USA, 58, 325.

Litman, J. D. (1986). Copyright compromise and legislative history. Cornell L. Rev., 72, 857.

Muth, R. F. (1983). Redistribution of Income Through Regulation in Housing. Emory LJ, 32, 691.

Nimmer, D. (1996). Brains and other Paraphernalia of the Digital Age. Harv. JL \& Tech., 10, 1.

Public Law 105 - 304 - Digital Millennium Copyright Act. govinfo. (1998, October 28). Retrieved from https://www.govinfo.gov/app/details/PLAW-105publ304

Samuelson, P. (1996). The copyright grab. Wired Magazine, 4.

Samuelson, P. (1996). The US digital agenda at WIPO. Va. J. Int' l L., 37, 369.

Samuelson, P. (1999). Intellectual Property and Contract Law for the Information Age: Foreword to a Symposium. Cal L. Rev., 87, 1. https://doi.org/10.2307/3481002

Samuelson, P. (1999). Intellectual property and the digital economy: Why the anti-circumvention regulations need to be revised. Berkeley Tech. $L J, 14,519$. https://doi.org/10.1145/318536.318538

Samuelson, P. (2003). Mapping the digital public domain: Threats and opportunities. Law \& Contemp. Probs., 66, 147.

Samuelson, P., \& Davis, R. (2000). The digital dilemma: A perspective on intellectual property in the information age. 28th Annual Telecommunications Policy Research Conference, Arlington, VA.

Samuelson, P., Nimmer, R. T., Gomulkiewicz, R. W., Litman, J., Ginsburg, J. C., Hutcheson, L. M., ... Cohen, J. E. (1998). Foreword to Symposium, Intellectual Property and Contract Law in the Information Age: The Impact of Article 2B of the Uniform Commercial Code on the Future of Transactions in Information and Electronic Commerce. Berkeley Tech. LJ, 13, 809.

Shapiro, C., Carl, S., \& Varian, H. R. (1998). Information rules: a strategic guide to the network economy. Harvard Business Press.

Yen, A. C. (2000). A preliminary economic analysis of Napster: internet technology, copyright liability, and the possibility of Coasean bargaining. U. Dayton L. Rev., 26, 247. https://doi.org/10.2139/ssrn.259550

Zech, H. (2015). Information as Property. Journal of Intellectual Property, Information Technology and Electronic Commerce Law, 6, 192-197.

Zech, H. (2016). Data as a Tradeable Commodity. In A. D. Franceschi (Ed.), European Contract Law and the Digital Single Market, Implications of the Digital Revolution (pp. 51-80). Cambridge: Intersentia. https://doi.org/10.1017/9781780685212.004

\section{Copyrights}

Copyright for this article is retained by the author(s), with first publication rights granted to the journal.

This is an open-access article distributed under the terms and conditions of the Creative Commons Attribution license (http://creativecommons.org/licenses/by/4.0/). 